\title{
CONHECIMENTOS PRÉVIOS DE EDUCAÇÃO AMBIENTAL PARA ALUNOS DO ENSINO FUNDAMENTAL
}

\author{
Amanda Paula de Araújo Silva ${ }^{1}$ \\ Hilda Helena Sovierzoski²
}

Resumo: A Educação Ambiental (EA) possibilita a formação de valores, a conscientização e a mudança de comportamento nas pessoas. Trata de uma ação contínua para tornar a população sensibilizada com as questões ambientais. O objetivo deste estudo foi conhecer os conhecimentos prévios dos alunos do $6^{\circ}$ ano do Ensino Fundamental sobre EA. A pesquisa foi de natureza qualitativa, com alunos de 2 turmas do $6^{\circ}$ ano. Foi aplicado um questionário com 7 questões objetivas e 1 questão discursiva. As respostas foram analisadas quanto à frequência e categorias. Os alunos possuíam conhecimentos sobre EA, mas demonstravam dificuldade em falar do tema e de entendimento. $O$ trabalho mostrou a importância de se trabalhar essa temática em sala de aula.

Palavras-chave: Conhecimentos Prévios; Anos Finais; Sensibilização.

Abstract: Environmental Education (EE) enables the formation of values, awareness and behavior change in people. It is an ongoing action to make the population aware of environmental issues. The aim of this study was to know the prior knowledge of students in the 6th grade of elementary school about EE. The research was qualitative in nature, with students from 2 classes of the 6th grade year. A questionnaire with 7 objective questions and 1 discursive question was applied. Answers were analyzed for frequency and categories. Students had knowledge about EE, but showed difficulty in talking about the topic and understanding. The work showed the importance of working on this theme in the classroom.

Keywords: Previous Knowledge; Final Years; Awareness.

1 Universidade Federal do Alagoas. E- mail: amandapasbio@gmail.com,

Link para o lattes: http://lattes.cnpq.br/2309959475737206

2 Universidade Federal do Alagoas. E-mail: hilda.sovierzoski@icbs.ufal.br.

Link para o lattes: http://lattes.cnpq.br/3044840899631023

Revbea, São Paulo, V. 17, № 1: 390-404, 2022. 


\section{Introdução}

A Educação Ambiental (EA) trabalha com os processos dos quais os indivíduos constroem valores e desenvolvem habilidades para modificar suas atitudes em relação ao meio ambiente. Desta forma, como o próprio indivíduo ocupa o ambiente onde vive, EA é necessária e urgente, afim de manter recursos naturais e evitar danos irreparáveis.

Teixeira (2007) entende a EA como um conjunto das teorias e práticas propostas a orientar o entendimento e estimular a percepção da pessoa para 0 respeito da importância de suas atitudes nas questões de conservação e preservação do meio ambiente. Macedo, Freitas e Venturin (2011) conceituam EA como uma ação contínua que busca tornar a população consciente e sensibilizada com as questões ambientais.

Segundo Giesta (2009), a EA trata de um conjunto de atividades que informam e sensibilizam as pessoas a respeito da temática ambiental, estimulando e promovendo práticas sustentáveis da utilização dos recursos naturais e proporcionando reflexões sobre a relação homem-meio ambiente. Braga (2010) traz sua interpretação de EA como um processo da relação entre sociedade e o meio, desenvolvida com base nas observações e reflexões sobre ela.

Reigota (2009) descreve a EA como uma educação política, pois se compromete em desenvolver a cidadania, a liberdade e a manifestação da busca de alternativas para a convivência e o bem comum. Para Seco e Sekine (2009) a EA deve ser empregada em todos os setores da sociedade, com os cidadãos empenhados em seus compromissos, o que envolveria escolas, professores e alunos.

Frequentemente o tema vêm sido discutido em eventos técnicos e políticos, e a Conferência Mundial sobre o Meio Ambiente Humano, fomentada pela Organização das Nações Unidas, conhecida como Conferência de Estocolmo, realizada em 1972, foi importante para seu desenvolvimento e aperfeiçoamento, e reuniu mais de uma centena de países, mais de duas centenas de ONG e várias unidades da ONU para discutir sobre as questões ambientais, bem como sua importância tem sido atestada em muitos documentos internacionais e nacionais (BARD et al., 2017).

Layrargues e Lima (2014) classificam a EA em três macrotendências diferentes: 1) a conservacionista (focada na conservação da natureza e na mudança de comportamento da população), 2) a EA pragmática (focando no desenvolvimento sustentável e cuidados para diminuição dos impactos) e 3) a EA crítica (que foca na relação produção com visão capitalista e preocupação do agravamento dos problemas ambientais). Neste trabalho foi tratada a EA pragmática, para obtenção do conhecimento dos alunos.

Observa-se que a presença da EA nas escolas trata de um componente curricular, mas como prática didática inter, multi e transdisciplinar, e deveria se desenvolver integralmente nos níveis e modalidades de ensino, da Educação 
Infantil ao Ensino Superior. A Política Nacional de Educação Ambiental (PNEA) recomenda que os professores estimulem os alunos ao desenvolvimento de habilidades, de comportamentos e de competências inclinadas para a conservação do ambiente, atitudes primordiais para a sustentabilidade e a melhoria na qualidade de vida (BRASIL, 1999).

De acordo com a Base Nacional Comum Curricular (BNCC) existe a preocupação com a questão ambiental trazer bem-estar para a população em geral pois "a crescente degradação ambiental, as mudanças climáticas e o aprofundamento das desigualdades sociais indicam que esse é um problema global que ainda carece de superação" (BRASIL, 2016, p. 51). A EA proporcionaria a conscientização, a transformação de comportamento e de valores, o desenvolvimento de competências, o aprimoramento de habilidades, estimulando a participação, a integração e o equilíbrio do aluno com o meio ambiente (PÁDUA; TABANEZ, 1998; REIGOTA, 1998).

Segundo Cavalcanti Neto e Amaral (2011, p. 131) para estimular uma educação cidadã faz-se necessária uma proposta educativa centrada "na conscientização, na mudança de atitude e de práticas sociais, no desenvolvimento de conhecimentos, na capacidade de avaliação e na participação dos educandos". A EA, de acordo com Ross e Becker (2012) objetiva apresentar uma metodologia em que cada indivíduo assume um papel no processo de ensino e de aprendizagem, sendo um agente ativo e participativo frente aos problemas socioambientais.

Para Ferreira, Rodrigues e Lima (2018), no âmbito escolar, os debates sobre os problemas ambientais parecem estar ausentes ou insuficientes para a promoção da transformação dos hábitos ambientais nos alunos do Ensino Fundamental e Médio. Para Dias (1992) um ambiente privilegiado para a realização de atividades que proporcionem reflexão são as escolas. França e Guimarães (2014, p. 3129) acreditam que "a Educação Ambiental quando praticada no ambiente educacional abre espaço para os estudantes conhecerem a problemática ambiental [...]" e dessa forma os alunos devem estar inseridos no meio ambiente, fazendo parte deste.

Medeiros et al. (2011) notam que as escolas reconhecem a importância de trabalhar os problemas ambientais e vem desenvolvendo iniciativas para inserir essa temática como tema transversal nos currículos escolares. No entanto existem dificuldades, sendo apontados 4 motivos principais para a dificuldade da transversalidade da EA na escola (BARBOSA, 2010, p. 28): "1 o modelo disciplinar escolar; 2 - a dificuldade de planejamento conjunto; 3 - a falta de incentivo à participação dos professores em projetos ambientais; e 4 - a formação insuficiente dos professores em temas socioambientais".

De acordo com Barros et al. (2009) há diferentes formas de se trabalhar EA nas escolas além das aulas em sala, como caminhar nos arredores da escola, participar de palestras e debates com a escola e comunidade, uso de músicas, construção de horta, desfile cívico, atividades artísticas, entre outras 
atividades. Sato (2002) afirma que as questões ambientais precisam ser consideradas como um todo, desconsiderando a ideia de isolamento e incluindo todas as áreas.

A expansão deste tema para a sala de aula mostra aos alunos que eles também fazem parte da natureza e que podem preservá-la. Muitas vezes, como afirma Reigota (2009, p. 11), "o ser humano contemporâneo vive profundas dicotomias. Dificilmente se considera elemento da natureza, mas um ser a parte, como um observador e/ou explorador dela". Por isto os impactos podem começar a diminuir quando o homem, de fato, perceber que depende do meio ambiente para sobreviver e que seus recursos são finitos.

Segundo Souza, Castro e Rosa (2016), a EA pode ser trabalhada por meio da conscientização e da realização de atividades simples, como o descarte correto do lixo e a reciclagem, além de conhecer algumas informações sobre os poluentes e qual a melhor forma de reduzi-los.

Neste trabalho considera-se lixo os resíduos sólidos, como embalagens de papelão, de plástico, de isopor, latas, vidros e garrafas que estejam sem restos alimentares, além dos próprios restos alimentares, como também as cascas de legumes, de frutas, folhas de hortaliças e embalagens que estejam sem a condição de ser lavadas, devidamente separadas, que por vezes são descartadas no denominado lixo doméstico.

Assim, Melo (2015) comenta que o conhecimento prévio dos alunos pode ser um indicador do comportamento familiar quanto às questões ambientais de modo geral. A mídia também exerce um papel importante sobre eles, influenciando na formação de seus conceitos. Para Miras (2006), os conhecimentos prévios dos alunos permitem a análise inicial de um novo assunto, atribuindo significados para dar início ao seu processo de aprendizagem.

De acordo com os Parâmetros Curriculares Nacionais (PCN) o professor precisa trabalhar com os alunos a temática de EA de forma a criar uma postura crítica diante da realidade falada em casa e apresentada na mídia (BRASIL, 1997). A BNCC reafirma o documento anterior, os PCN, ao abordar o sentido de pertencimento do homem no ambiente, a partir da compreensão da capacidade de desenvolvimento do respeito pelos seres vivos e pelo mesmo meio ambiente (BRASIL, 2017).

O artigo objetivou conhecer os conhecimentos prévios dos alunos do $6^{\circ}$ ano do Ensino Fundamental sobre EA.

\section{Procedimentos Metodológicos}

A pesquisa realizada foi do tipo qualitativa. Godoy (1995) afirmou que na pesquisa qualitativa o pesquisador buscaria o fenômeno baseado na perspectiva dos participantes e consideraria que os pontos de vista são relevantes. 
O trabalho foi desenvolvido em uma escola pública do Estado de Alagoas, integrante do Complexo Educacional de Pesquisa Aplicada (CEPA) da Secretaria de Estado da Educação de Alagoas, com a participação de estudantes pertencentes a duas turmas do 6을 ano do Ensino Fundamental. A participação ocorreu com 28 estudantes, somando as duas turmas. As duas turmas tinham atividades escolares no período da manhã. A coleta de dados aconteceu no mês de novembro de 2019. O início foi desenvolvido com o Teste Diagnóstico (TD) e seguiu com oficinas em três semanas seguintes.

Esta pesquisa utilizou os conhecimentos prévios dos estudantes. Para o reconhecimento dos saberes prévios foi aplicado um Teste Diagnóstico (TD), que constou de um questionário semiestruturado, com sete questões objetivas e as opções de escolha: "sim", "não" e "não quero responder", além de uma questão discursiva (Quadro 1). O mesmo questionário foi aplicado nas duas turmas e participaram desta etapa 28 estudantes. Segundo Marconi e Lakatos (2009), os questionários apontariam muitas vantagens, dentre elas a possibilidade de coleta de informações, comparação objetiva entre as respostas, garantia do anonimato das respostas, entre outras.

Quadro 1: Questões apresentadas no Teste Diagnóstico (TD) para os alunos do 6ํano do Ensino Fundamental.

1. Você se sente parte da natureza? ( ) Sim ( ) Não ( ) Não quero responder

2. A Educação Ambiental faz parte do seu dia-a-dia?

( ) Sim ( ) Não ( ) Não quero responder

3. É possível reutilizar materiais que seriam descartados no lixo?

( ) Sim ( Não ( ) Não quero responder

4. Você conhece alguma ação positiva para o meio ambiente? ( ) $\operatorname{Sim}()$ Não ( ) Não quero responder

5. Os impactos negativos provocados pelo homem estão ligados à degradação do ambiente? ( ) Sim ( ) Não ( ) Não quero responder

6. Aulas diferentes (usando histórias em quadrinhos, fotografia, aula de campo) ajudam a entender melhor esses assuntos? ( ) Sim ( ) Não ( ) Não quero responder

7. Você acredita que as oficinas ajudarão na compreensão da Educação Ambiental?

( ) Sim ( ) Não ( ) Não quero responder

8. Qual seria a sua ação para evitar a degradação ambiental?

Fonte: Autoria Própria (2021).

Os estudantes consentiram sua participação na pesquisa por meio da assinatura do TALE (Termo de Assentimento Livre e Esclarecido) e os pais e/ou responsáveis autorizaram a participação dos menores com a assinatura do TCLE (Termo de Consentimento Livre e Esclarecido), registrados e aprovados na Plataforma Brasil, sob Protocolo nำ 18385619.0.0000.5013. 
As questões objetivas do TD foram analisadas por frequência de respostas e a questão discursiva por categorização, baseada em Bardin (2011) compilando as respostas afins. Os resultados das questões objetivas de ambas as turmas foram reunidos e os dados brutos transformados em percentual. Segundo Carlomagno e Rocha (2016), a metodologia de análise de conteúdos buscaria a classificação e categorização dos conteúdos, sintetizando suas características e elementos-chave.

\section{Resultados e Discussão}

Quando os alunos foram questionados se fazem parte da natureza a maioria respondeu sim, $82 \%$ dos participantes (Figura 1). Diferindo desse resultado, Camboim e Barbosa (2012) constataram que a maioria dos alunos observa o meio ambiente resumido ao aspecto natural, sem considerar a sociedade como um de seus componentes. Dias-da-Silva e Santos (2019) relataram que $68 \%$ dos alunos dominavam a visão reducionista, pois percebiam o meio ambiente apenas por seus aspectos físicos naturais, excluindo o ser humano e suas ações.

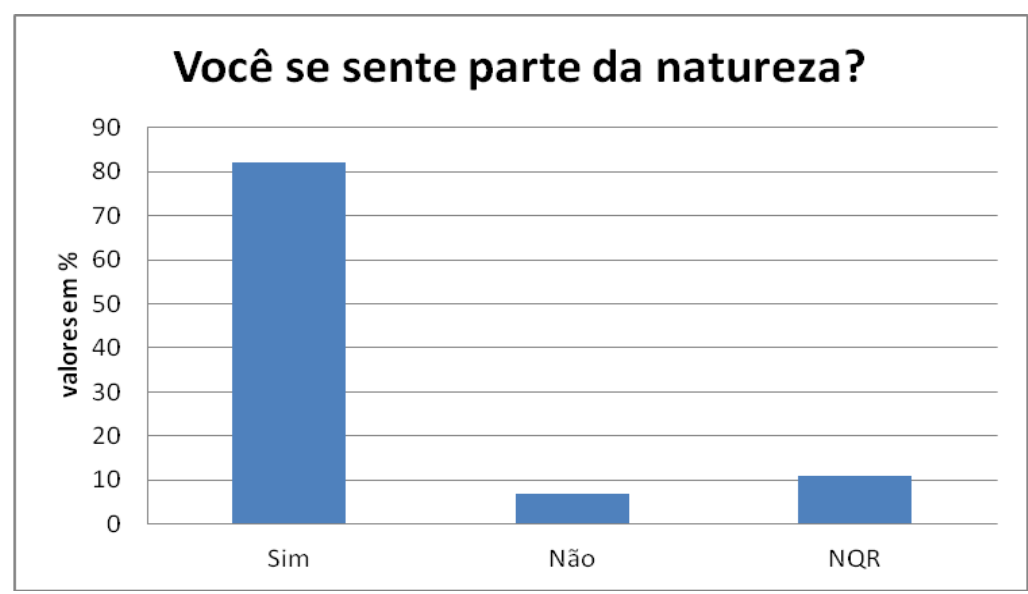

Figura 1: Relação de pertencimento na natureza.

Fonte: Autoria Própria (2021).

Ao analisar a questão se a EA faz parte do cotidiano dos alunos registrou-se que $89 \%$ dos alunos assinalaram sim. Notou-se ainda que $4 \%$ dos alunos escreveram "mais ou menos" como uma opção que faltava. Carneiro, Oliveira e Moreira (2016) consideraram que o professor, quando possível, poderia possibilitar a aplicação dos conhecimentos para a realidade local, de forma que o aluno se sentisse capaz de contribuir com o meio ambiente e exercesse sua cidadania desde cedo (Figura 2). 


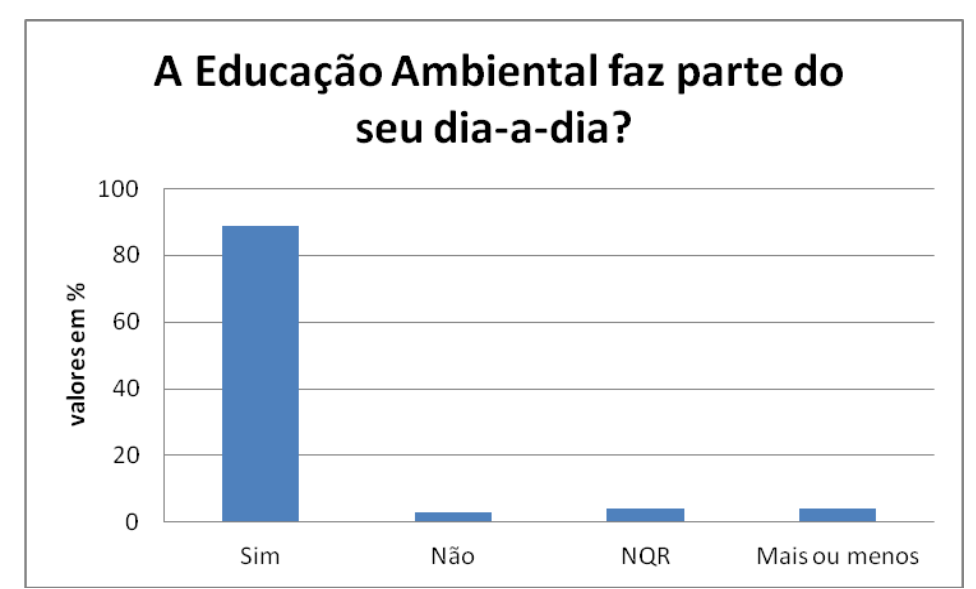

Figura 2: Integração de Educação Ambiental e o cotidiano dos alunos.

Fonte: Autoria Própria, 2021.

$\mathrm{Na}$ questão sobre a reutilização de materiais descartados $86 \%$ responderam positivamente. Uma grande parte dos estudantes possui conhecimentos prévios sobre os materiais que podem ser reutilizados (Figura 3). Nascimento, Santos e Nunes (2019) compreenderam o conhecimento dos participantes sobre reciclagem de materiais utilizados em suas residências, percebendo preocupação destes quanto ao armazenamento dos materiais.

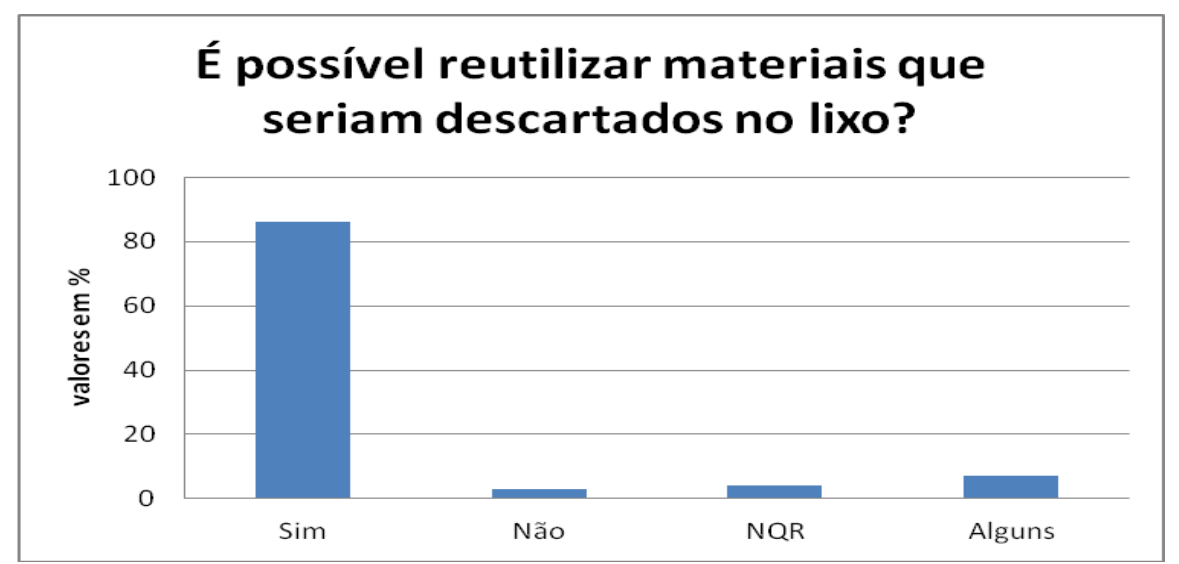

Figura 3: Reuso de materiais descartados.

Fonte: Autoria Própria, 2021.

Analisando a questão sobre ações positivas para o meio ambiente, observou-se que $36 \%$ dos discentes desconhecem qualquer tipo de ação para preservação da natureza. Devido ao número considerado de estudantes que desconhecem alguma ação positiva, ressalta-se a importância de projetos e trabalhos desenvolvidos no ambiente escolar sobre EA (Figura 4). Cavalcante (2016) perguntou sobre alternativas para amenizar a problemática ambiental, sendo que $45 \%$ dos estudantes indicaram a "reciclagem e a reutilização para diminuição da quantidade de resíduos no meio ambiente"; $41 \%$ afirmaram que "não se deve jogar lixo na rua" e 14\% não souberam responder, demonstrando a compreensão sobre as mudanças para um ambiente mais sustentável. 


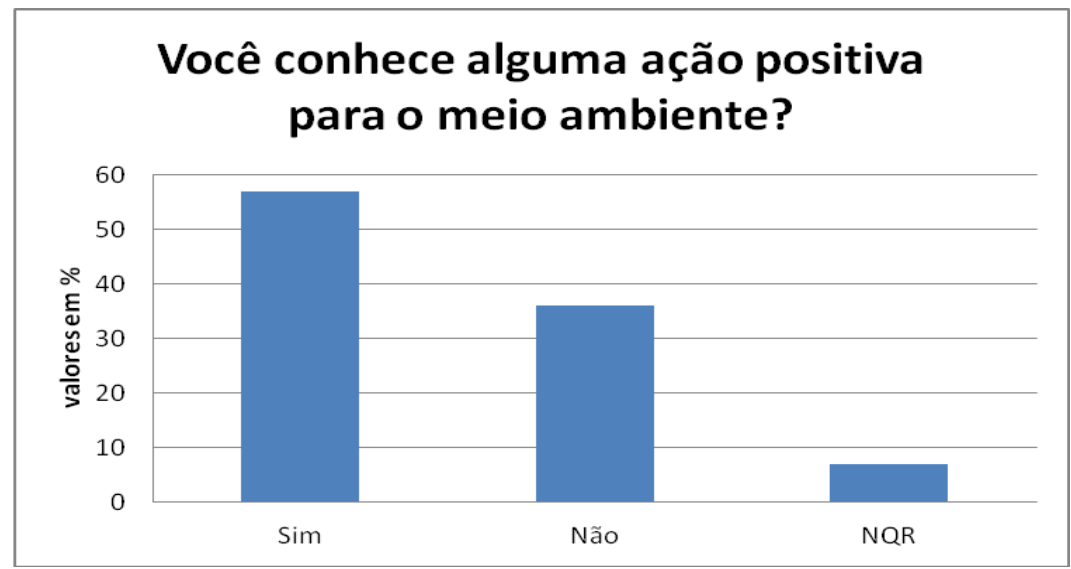

Figura 4: Conhecimento de ações positivas para o meio ambiente.

Fonte: Autoria Própria (2021).

Quando questionados sobre a relação entre impactos negativos provocados pelo homem e degradação ambiental, 54\% dos participantes afirmaram que existe essa relação. Devido ser um tema de grande relevância e repercussão, chamou atenção $25 \%$ dos estudantes deixarem de responder essa pergunta (Figura 5).

Corroborando com esta pesquisa, Eckert et al. (2017) analisaram desenhos produzidos pelos estudantes, perceberam que $95,4 \%$ dos desenhos foram categorizados como negativos, mostrando que os estudantes conseguem perceber que a ação humana causa danos irreparáveis para o meio ambiente. Dias-da-Silva e Santos (2019) questionaram os discentes sobre "quem são os responsáveis pelo surgimento de problemas ambientais?" e obtiveram como resultado que são "as pessoas" (64\%), "o governo" $(27 \%)$, e "nós mesmos" (9\%), com os participantes se excluindo como causadores dos problemas ambientais.

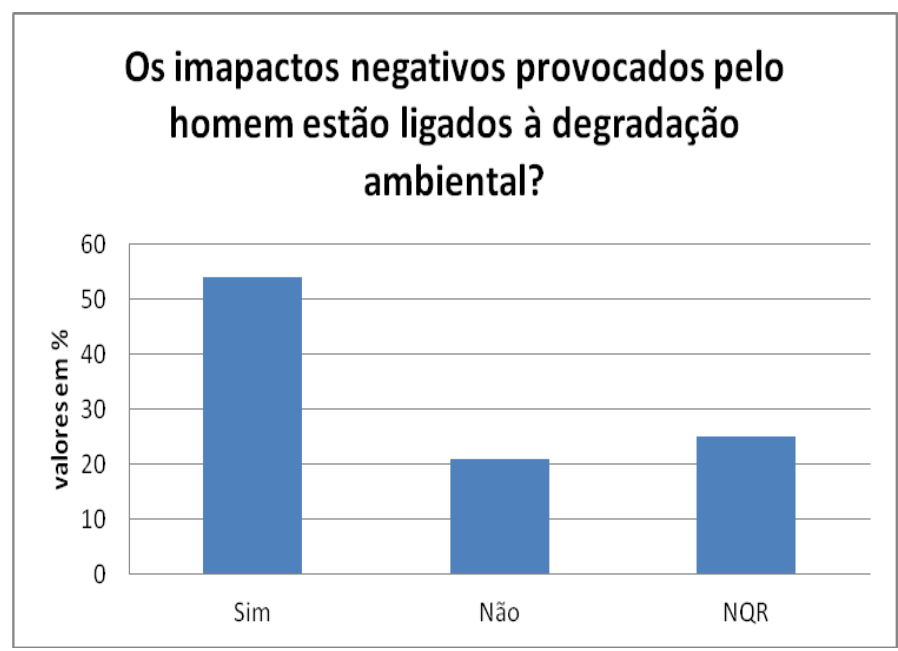

Figura 5: Relação entre degradação do meio ambiente e ação humana.

Fonte: Autoria Própria (2021). 
Sobre a questão "Aulas diferentes (usando histórias em quadrinhos, fotografia, aula de campo) ajudam a entender melhor os assuntos?" $89 \%$ dos estudantes afirmaram que a utilização de diferentes ferramentas colabora no processo de aprendizagem e $11 \%$ deixaram de responder. Com poucas respostas negativas, observou-se a inclinação dos estudantes na utilização de diferentes metodologias pelo professor para atender as diferentes formas de aprendizagem (Figura 6). Muline e Campos (2016) constataram que os discentes se sentiram atraídos pela confecção de desenhos e expressaram sua concepção sobre meio ambiente, refletindo sobre as questões ambientais.

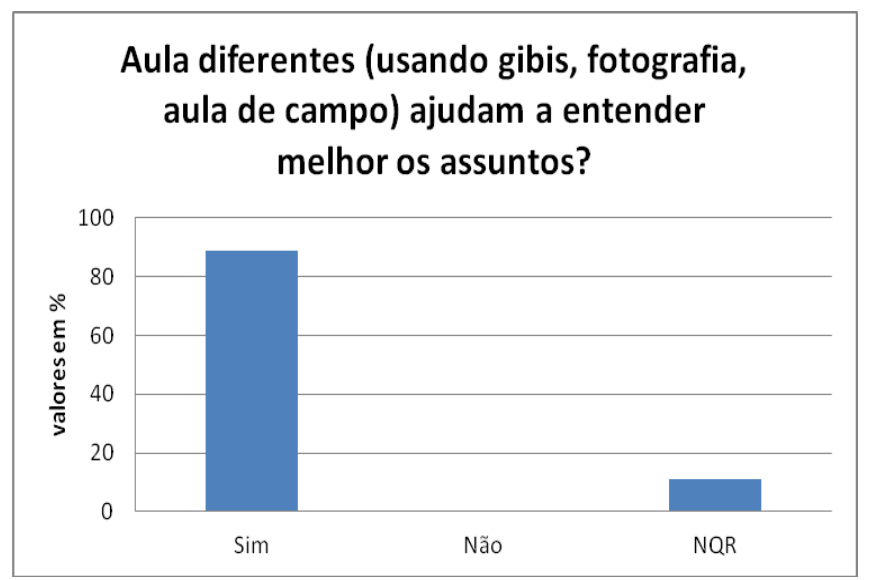

Figura 6: Utilização de diferentes ferramentas no processo de aprendizagem.

Fonte: Autoria Própria (2021).

Ao abordar a importância das oficinas (a serem tratadas em outra pesquisa) na compreensão da EA, $53 \%$ dos alunos responderam que as oficinas ajudariam nesse processo e $4 \%$ escreveram "não sei" referente à importância das oficinas na compreensão da EA (Figura 7). Nascimento, Santos e Nunes (2019) inferiram que as oficinas são eficientes na sensibilização sobre o tema Meio Ambiente.

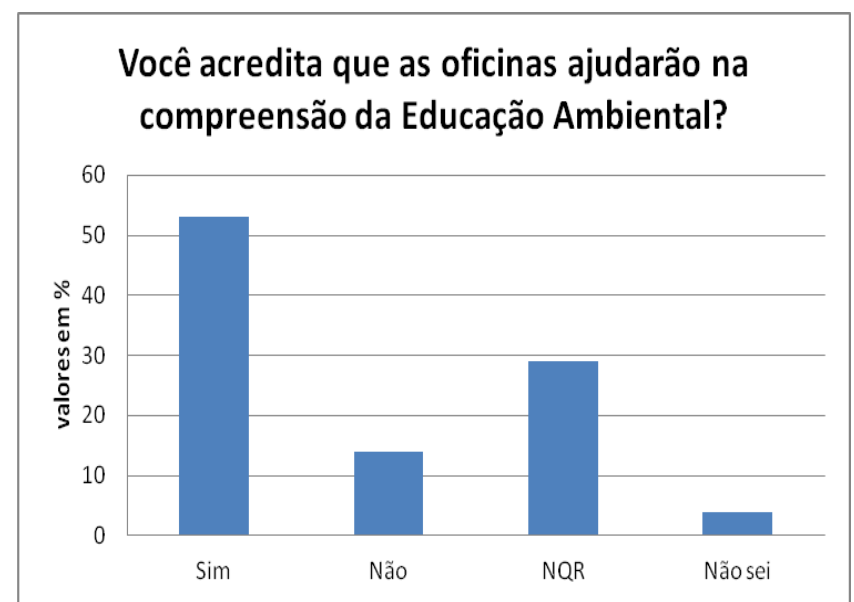

Figura 7: Compreensão da Educação Ambiental por meio de oficinas.

Fonte: Autoria Própria (2021). 
Para a questão discursiva, utilizou-se categorização das respostas para a pergunta "Qual seria a sua ação para evitar a degradação ambiental?". De acordo com Bardin (2011, p.44), análise do conteúdo significa:

um conjunto de técnicas de análise das comunicações visando obter, por procedimentos sistemáticos e objetivos de descrição do conteúdo das mensagens, indicadores (quantitativos ou não) que permitam a inferência de conhecimentos.

As categorias obtidas foram descritas de acordo com o número de vezes que apareceram em alguma resposta (Figura 8). Em alguns casos, em uma mesma resposta, foram encontradas categorias diferentes, sendo marcadas mais de uma vez, portanto.

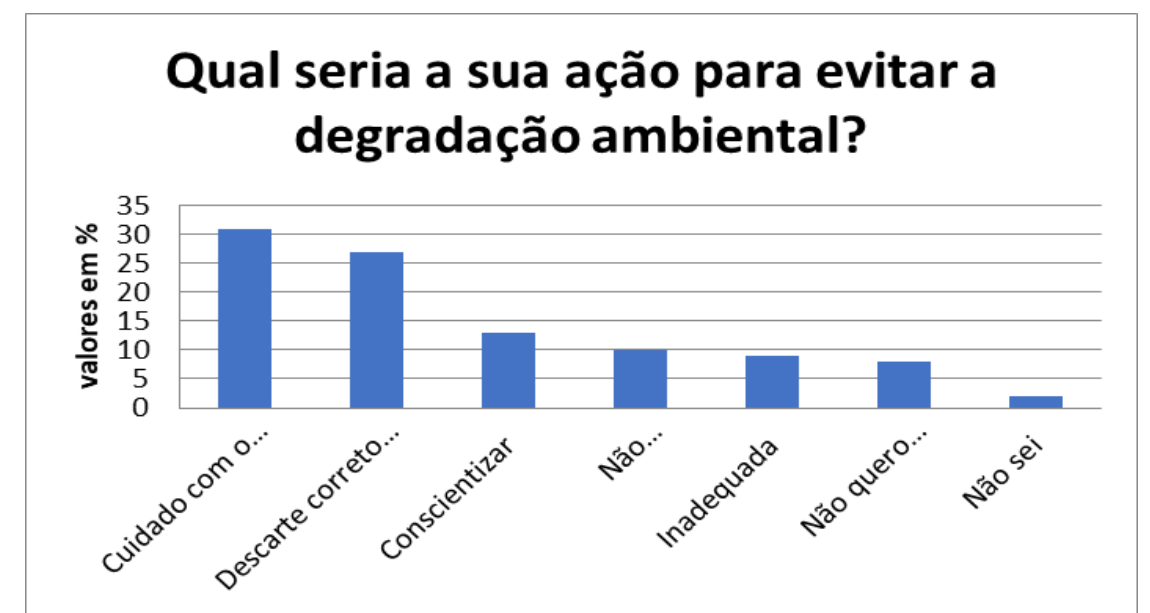

Figura 8: Categorias extraídas quanto ao questionamento sobre ações para evitar a degradação ambiental.

Fonte: Autoria Própria (2021).

A categoria mais identificada nas respostas dos estudantes foi a nomeada "Cuidado com o meio ambiente" 16 vezes (31\%), seguida da categoria "Descarte correto do lixo" 14 vezes (27\%). A categoria "Inadequada" foi encontrada em cinco respostas ( $9 \%$ ). A categoria "Conscientizar" chamou a atenção pelo fato dos discentes informarem outras pessoas sobre a temática (sete vezes, 13\%) ressaltando a importância do conhecimento dos estudantes, pois levam esta temática para sua casa e comunidade. Pinheiro e Rocha (2018) perceberam que, no contexto escolar, pode-se identificar que o estudante, ao ser sensibilizado para as questões ambientais, se aproxima e faz relação com o espaço em que vive, tornando-se um multiplicador desse conhecimento em sua comunidade.

Foram extraídas algumas respostas dos estudantes no Quadro 2. Durante a análise dos dados, foi possível perceber semelhança entre algumas respostas dos estudantes. 
Quadro 2: Respostas dos alunos de acordo com a categoria (as frases em itálico reproduzem as produções dos alunos).

\begin{tabular}{|l|l|}
\hline CATEGORIA & RESPOSTAS \\
\hline Inadequada & $\begin{array}{l}\text { Um novo presidente. } \\
\text { Cuide bem da escola, ela também é a sua casa. } \\
\text { Eu gosto da natureza, tem gente que joga lixo, eu amo a } \\
\text { natureza. }\end{array}$ \\
\hline Não sei & Eu não sei direito. \\
\hline Descarte correto do lixo & $\begin{array}{l}\text { Não jogar lixo na rua. } \\
\text { Reutilizar o lixo, não jogar lixo na rua, não jogar lixo na praia. } \\
\text { Não jogar lixo na rua, reciclar garrafas e plásticos, limpar a } \\
\text { cidade, só jogar lixo na lixeira. }\end{array}$ \\
\hline Não desmatar/Plantar & $\begin{array}{l}\text { Não praticar desmatamento. } \\
\text { Não cortaria árvores, nem construiria muitos edifícios. } \\
\text { Plantar mais árvores em cidades para purificar o ar. }\end{array}$ \\
\hline Conscientizar & $\begin{array}{l}\text { Incentivar as pessoas a cuidar do meio ambiente, relatar o } \\
\text { risco de nós não cuidarmos do ambiente. } \\
\text { Compartilhar com as pessoas manter a cidade limpa. } \\
\text { Dar palestra sobre esse assunto (lixo). }\end{array}$ \\
\hline Cuidado com o meio ambiente & $\begin{array}{l}\text { Construir mais parques. } \\
\text { Cuidar do meio ambiente. } \\
\text { Não tocar fogo na natureza. } \\
\text { Não poluir o meio ambiente. } \\
\text { Parar de gastar muita água sem precisão. } \\
\text { Não matar os animais, pois eles fazem parte da natureza. }\end{array}$ \\
\hline
\end{tabular}

Fonte: Autoria Própria (2021).

Confirmando com o resultado obtido nas categorias "Não desmatar/Plantar", "Descarte correto do lixo" e "Cuidado com o meio ambiente", Dias-da-Silva e Santos (2019), ao questionarem os estudantes "como as pessoas podem melhorar o ambiente em que vivem?", que as respostas indicadas foram "não jogar lixo no chão" (36\%), "não poluir rios e mares" $(30 \%)$, efetivar "saneamento básico" (20\%), "separar lixo" (8\%) e "plantar árvores" (6\%). Assim, com os dados obtidos nas duas pesquisas, foi possível perceber que os estudantes se preocupam com os problemas ambientais e compreendem que métodos simples podem diminuir tais problemas.

Um pequeno percentual dos estudantes (2\%) relatou desconhecer quais os meios para se evitar a degradação ambiental assim como $9 \%$ respondeu de forma inadequada, revelando à necessidade de se trabalhar a EA de forma mais efetiva em sala de aula. Furtado e Martin (2016) ao indagarem os 
estudantes sobre "o que seria a Educação Ambiental", notaram que os pesquisados responderam à pergunta de forma inaceitável, a grande maioria narrou que é apenas "cuidar da natureza".

\section{Considerações Finais}

Os participantes da pesquisa demonstraram conhecimentos prévios sobre o tema abordado, porém ainda apresentando respostas inadequadas, sem saber ou sem querer responder alguns questionamentos. A EA na escola precisa ser revista, uma vez que a sensibilização muitas vezes está focada apenas na teoria, sendo necessária a inserção de diferentes metodologias que coloquem os estudantes como seres ativos.

As respostas envolvendo o termo "lixo" apareceram com frequência, mostrando que os estudantes têm mais contato em seu cotidiano ou ainda que se encontra muito disseminado por meio de propaganda na mídia. Os estudantes reconhecem a possibilidade de reutilizar materiais que seriam descartados.

Os alunos comentaram que o uso de diferentes ferramentas para o ensino de EA colaboram no processo de aprendizagem. Sugere-se fortemente o uso de diferentes atividades com os alunos de Ensino Fundamental quanto às questões relativas a EA.

\section{Agradecimentos}

Ao Programa de Pós-Graduação em Ensino de Ciências e Matemática (PPGECIM) da Universidade Federal de Alagoas pela oportunidade de aprendizados e experiências de mestrado.

\section{Referências}

BARD, E. et al. Educação Ambiental, conceitos, histórico, concepções e comentários à lei da Política Nacional de Educação Ambiental (Lei no 9.795/99). Programa de Pós-Graduação em Direito Ambiental da UEA: Dissertação de mestrado em Direito Ambiental (org. Eid Badr). Manaus: Editora Valer, 2017.

BARDIN, L. Análise de conteúdo. São Paulo: Edições 70, 2011.

BARROS, A.L. et al. Agenda Ambiental Escolar, 2009. Disponível em:<https://semed.manaus.am.gov.br/wp-content/uploads/2010/10/Revisada18-de-maio-de-2009.pdf>. Acesso em: 01 de junho de 2020.

BARBOSA, G.S. Olhares sobre a Educação Ambiental na escola: as práticas e as estratégias educativas de implementação. Educação em foco, Juiz de Fora, v. 14, n. 2, p.71-93, 2010. 
BRAGA, A.R. Meio ambiente e educação: uma dupla de futuro. Campinas: Mercado das Letras, 2010.

BRASIL. Secretaria de Educação Fundamental. Parâmetros Curriculares Nacionais: meio ambiente e saúde. Brasília, DF, 1997. Disponível em:< http://portal.mec.gov.br/seb/arquivos/pdf/meioambiente.pdf>. Acesso em $30 \mathrm{de}$ março de 2020.

BRASIL. Ministério da Educação. Base Nacional Comum Curricular - BNCC. DF, 2016. Disponível em:< http://basenacionalcomum.mec.gov.br/historico $>$. Acesso em 15 de dezembro de 2019.

BRASIL. Base Nacional Comum Curricular. Brasília: MEC, 2017. Disponível em:< http://basenacionalcomum.mec.gov.br/historico $>$. Acesso em $15 \mathrm{de}$ dezembro de 2019.

CAMBOIM, J.F.F.; BARBOSA, A.G. Estratégias de Educação Ambiental por meio da atuação da COM-VIDA: vivências em uma escola do Recife-PE. HOLOS, v. 1, p.124-136, 2012.

CARLOMAGNO, M.C.; ROCHA, L.C. da. Como criar e classificar categorias para fazer análise de conteúdo: uma questão metodológica. Revista Eletrônica de Ciência Política, v. 7, n. 1, p.173-188, 2016.

CARNEIRO, B.S.; OLIVEIRA, M.A.S.; MOREIRA, R.F. Educação Ambiental na escola pública. Revista Brasileira de Educação Ambiental, v. 11, n. 1. p.2536, 2016.

CAVALCANTE, M.B. Percepção ambiental sobre os resíduos sólidos: relato de experiência na educação básica. In: EL-DEIR, S.G.; AGUIAR, W.J. de; PINHEIRO, S.M.G. (orgs.). Educação Ambiental na gestão de resíduos sólidos. Recife: EDUFRPE, 2016.

CAVALCANTI NETO, A.L.G.; AMARAL, E.M.R. do. Ensino de ciências e Educação Ambiental no nível fundamental: análise de algumas estratégias didáticas. Ciência \& Educação, v. 17, n. 1, p.129-144, 2011.

DIAS, G.F. Educação Ambiental: princípios e práticas. São Paulo, Gaia, 1992.

DIAS-DA-SILVA, C.D.; SANTOS, D.B. Percepção de estudantes do ensino fundamental sobre o meio ambiente e a Educação Ambiental. UNISANTA Bioscience, v. 8, n. 2, p.173-184, 2019.

ECKERT, N.O.S et al. Percepção ambiental de estudantes da zona rural sobre a Reserva Biológica de Santa Isabel, Pirambu (SE). Revista Brasileira de Educação Ambiental, v. 12, n. 1, p.43-57, 2017.

FERREIRA, A.T.S.; RODRIGUES, E.C.V.; LIMA, E.M. Educação Ambiental e alimentar a curto prazo através do ensino de ciências. Ensino, Saúde e Ambiente, v. 11, n. 3, p.218-240, 2018. 
FRANÇA, P.A.R.; GUIMARÃES, M.G.V. A Educação Ambiental nas Escolas Municipais de Manaus (AM): um estudo de caso a partir da percepção dos discentes. REMOA, v. 14, n. 2, p.3128-3138, 2014.

FURTADO, J.C.A.; MARTIN, A.M.C.B. Educação Ambiental em escolas públicas de Santa Inês (MA): mobilizando e criando. Revista Brasileira de Educação Ambiental, v. 11, n. 1, p.108-116, 2016.

GIESTA, L.C. Cartilha de Gestão Ambiental. 2009. Disponível em: $<$ http://www2.ufersa.edu.br/portal/view/uploads/setores/241/Cartilha\%20Gest\% C3\%A30\%20Ambiental.pdf>. Acesso em: 01 de junho de 2020.

GODOY, A.S. Pesquisa qualitativa: tipos fundamentais. Revista de Administração de Empresas, v. 35, n.3, p.20-29, 1995.

LAYRARGUES, P.P.; LIMA, G.F.C. As macrotendências político-pedagógicas da Educação Ambiental brasileira. Ambiente \& Sociedade, v. 17, n. 1, p.2340, 2014.

MACEDO, R.L.G.; FREITAS, M.R.; VENTURIN, N. Educação Ambiental: referenciais teóricos e práticos para a formação de educadores ambientais. Lavras: UFLA, 2011.

MARCONI, M.A.; LAKATOS, E.M. Metodologia Científica: ciência e conhecimento científico; métodos científicos; teoria, hipóteses e variáveis; metodologia jurídica. São Paulo: Atlas, 2009.

MEDEIROS, A.B.; MENDONÇA, M.J.S. L.; SOUSA, G.L.; OLIVEIRA, I.P. A Importância da Educação Ambiental na escola nas séries iniciais. Revista Faculdade Montes Belos, v. 4, n. 1, p.1-17, 2011.

MELO, M.G. Educação Ambiental na escola. 2015. Trabalho de Conclusão de Curso (Graduação em Pedagogia) - Universidade Estadual da Paraíba, Campina Grande. Disponível em: $<$ http://dspace.bc.uepb.edu.br/jspui/handle/123456789/9734>. Acesso em: 14 de dezembro de 2019.

MIRAS, M. O ponto de partida para a aprendizagem de novos conteúdos: os conhecimentos prévios. In: COLL, C. (org.). O construtivismo em sala de aula. São Paulo: Ática, 2006.

MULINE, L.S.; CAMPOS, C.R.P. Uma sequência didática para trabalhar a Educação Ambiental crítica com alunos das séries iniciais do ensino fundamental. Revista Práxis, v. 8, n. 16, p.105-114, 2016.

NASCIMENTO, A.T.B.S.; SANTOS, I.F.; NUNES, J.R.V. Oficinas educativas/reflexivas e a interface com saúde e o meio ambiente. Em Extensão, Uberlândia, v. 18, n. 1, p.134-144, 2019.

PÁDUA, S.; TABANEZ, M. (orgs.). Educação Ambiental: caminhos trilhados no Brasil. São Paulo: Ipê, 1998. 
PINHEIRO, R.F.; ROCHA, M.B. Contribuição de uma sequência didática no ensino de ciências para combate ao Aedes aegypti. Ensino, Saúde e Ambiente, v. 11, n. 3, p.186-201, 2018.

REIGOTA, M. Desafios à Educação Ambiental escolar. In: JACOBI, P. et al. (orgs.). Educação, meio ambiente e cidadania: reflexões e experiências. São Paulo: SMA, 1998.

REIGOTA, M. O que é Educação Ambiental. São Paulo: Brasiliense, 2009.

ROSS, A.; BECKER, E.L.S. Educação Ambiental e sustentabilidade. Revista Eletrônica em Gestão, Educação e Tecnologia Ambiental, v. 5, n. 5, p.857866, 2012.

SATO, M. Educação Ambiental. São Carlos: Rima, 2002.

SECO, M.A.O.; SEKINE, E.S. Educação Ambiental. Cuiabá: EduUFMT, 2009.

SOUZA, J.C.; CASTRO, J.D.B.; ROSA, I.R. Educação Ambiental na escola. In: CASTRO, J.D.B. (org.). Anápolis, desafios ambientais. Anápolis-GO: Editora UEG, 2016.

TEIXEIRA, A.C. Educação Ambiental: caminho para a sustentabilidade. Revista Brasileira de Educação Ambiental, n. 2, p. 23-32, 2007. 